\title{
A Contribuição da Educação Ambiental para a Percepção Acerca do Consumo Sustentável
}

\section{The Contribution of Environmental Education to Perception about Sustainable Consumption}

\author{
Camila Fritzen Cidón*a; Dusan Schreiber ${ }^{\text {abc}}$; Giseli Vecchietti ${ }^{\text {ad }}$ \\ aUniversidade FEEVALE, Programa de Pós-Graduação Stricto Sensu em Qualidade Ambiental. RS, Brasil. \\ bUniversidade FEEVALE, Programa de Pós-Graduação Stricto Sensu em Administração. RS, Brasil. \\ 'Universidade FEEVALE, Programa de Pós-Graduação Stricto Sensu em Indústria. RS, Brasil. \\ ${ }^{d}$ Rede Estadual de Ensino do Estado do Rio Grande do Sul. RS, Brasil. \\ *E-mail: camila_cidon@hotmail.com
}

\begin{abstract}
Resumo
O comportamento de consumo indica decisões e preferências que são adotadas de forma progressiva na incorporação da ideia de que preocupações ambientais são importantes, gerando a percepção individual de que a justiça para com o meio ambiente está sendo promovida. A educação ambiental (EA) dos sujeitos prevê o envolvimento de um conjunto de atores sociais que busquem ações alternativas ao modelo de desenvolvimento corrente, que instiga os educandos para a análise crítica dos problemas socioambientais, derivados do consumo crescente e irresponsável para com o meio ambiente. Dessa forma, este estudo de caso exploratório pretende investigar, junto a graduandos de ensino superior, qual o grau de consciência ecológica desses indivíduos quanto a suas escolhas cotidianas, bem como a influência da educação formadora em seu comportamento. Para isso, um questionário foi aplicado em uma turma de graduação em uma universidade do Rio Grande do Sul. Os resultados demonstraram que, apesar do amplo conhecimento dos principais problemas ambientais e da capacidade individual de transformação da realidade, e decisões de consumo que eventualmente contemplam os critérios de sustentabilidade, falta ampliar práticas mais sustentáveis no momento da escolha como consumidor. Tal achado pode ser explicado pela carência de estímulos no ambiente escolar, tão importante para a formação crítica e cidadã dos indivíduos. Como contribuição prática, sugere-se replicar o estudo em outros ambientes escolares, inclusive em diferentes níveis de ensino. Embora o número amostral da pesquisa seja reduzido, as respostas obtidas poderão servir para embasamento na formulação de métodos de aprendizagem que possam estimular o consumo responsável.
\end{abstract}

Palavras-chave: Consumo Consciente. Sustentabilidade. Meio Ambiente.

\begin{abstract}
Consumer behavior indicates decisions and preferences that are gradually adopted to incorporate the idea that environmental concerns are important, generating an individual perception that justice for the environment is being promoted. The subjects' environmental education provides for the involvement of a set of social actors that seek alternative actions to the current development model, which encourages students to critically analyze socio-environmental problems, derived from the growing and irresponsible consumption of the environment. In this way, this exploratory case study aims to investigate, together with undergraduate students, what is the degree of ecological awareness of these individuals regarding their daily choices, as well as the influence of training education on their behavior. For this, a questionnaire was applied to an undergraduate class at a university in Rio Grande do Sul. The results showed that, despite the wide knowledge of the main environmental problems and the individual capacity to transform reality, and consumption decisions that eventually contemplate the sustainability criteria, it is necessary to expand more sustainable practices when choosing as a consumer. This finding can be explained by the lack of stimuli in the school environment, which is so important for the critical and citizen education of individuals. As a practical contribution, it is suggested to replicate the study in other school environments, including at different levels of education. Although the sample number of the research is small, the answers obtained may serve as a basis for the formulation of learning methods that can stimulate responsible consumption.
\end{abstract}

Keywords: Conscious Consumption. Sustainability. Environmental.

\section{Introdução}

As mudanças climáticas são um dos principais temas presentes nos debates da sociedade, tanto na esfera acadêmica, midiática, política e social. Seus efeitos, como aumento da temperatura terrestre, degelo das calotas polares, perda de hábitats e de espécies, aumento de desastres naturais, agravamento de problemas de saúde na população, escassez de alimentos, passam a ser cada vez mais percebidos pela sociedade, e a comprovação intrínseca do fator antropogênico como causador e agravador desses efeitos, vem provocando a necessidade de mudanças em todas as dimensões sociais.
AEA emergiu no início da década de 60 como uma resposta necessária para emergentes crises ambientais. Desde então tentou-se desenvolver a alfabetização ecológica necessária para a compreensão dos contextos políticos, dos valores sociais derivados do consumo desmedido e consequentemente os problemas ambientais que vinham surgindo (WALS et al., 2014).

Apesar de iniciarem as primeiras discussões apenas na década sessenta, do século passado, percebe-se, ainda, a reduzida influência da dimensão ambiental sobre a cultura de consumo, sugerindo que o sistema educacional vem 
apresentando falhas na formação da educação ecológica dos indivíduos (SILVA; COSTA; BORBA, 2016). Mesmo com previsões legais e regulamentares, que recomendam a adoção de práticas educacionais para ensinar noções de sustentabilidade e ecologia em temas transversais, a orientação simbólica do sistema educacional, para o consumo, ainda é preponderante.

Considerando-se que, de forma geral, o modelo dominante de ensino remete à competição de mercado e à formação técnica científica, onde muitas vezes se incentiva o consumo irrefletido, pode-se afirmar que a base estruturante da sociedade atual, é a crença de que a sociedade só se desenvolverá com mais produção e consumo (SILVA; COSTA; BORBA, 2016). Para que a EA possa sensibilizar a sociedade, é necessário perceber que é o comportamento humano que causa a poluição, para, assim iniciar o processo de identificação de formas para envolver a comunidade local.

Essa deverá ser a tendência da EA a favor da convergência do aumento do interesse do cidadão pela temática de sustentabilidade, com as tecnologias da informação e comunicação, para aumentar a resposta da educação aos desafios globais atuais (WALS et al., 2014). Nesse sentido, os educadores podem reforçar o engajamento da sociedade ensinando que o conhecimento, as habilidades e uma mudança comportamental podem contribuir para a redução da emissão de gases de efeito estufa (SILVA; COSTA; BORBA, 2016).

Porém, o engajamento necessário e a prática educacional, com orientação para a sustentabilidade, só serão possíveis após a tomada de consciência de que as atividades antrópicas, além de influenciarem nas estruturas sociais e econômicas, estão intensificando as mudanças do clima. O comportamento reflexivo e engajado obtido por meio da EA, favorece as mitigações das causas e efeitos das mudanças climáticas, favorecendo a adaptação e o aumento de consciência (SILVA; COSTA; BORBA, 2016).

A EA não deve ser vista apenas como inspiração para a gestão ambiental e cidadania responsável, mas deve se aprofundar na proteção da sociedade contra os efeitos nocivos causados por ela mesma, através da intensa produção industrial e consumo desenfreado (STRIFE, 2010). EA não é neutra, mas ideológica. É um ato político, baseado em valores para a transformação social (REZENDE, 2014).

O comportamento verde não é apenas o resultado de condições de controle estatal por meio de normas sociais, mas surge dos valores intrapessoais mantidos pelos cidadãos. Até porque, somente o Estado sozinho não será capaz de resolver os problemas ambientais decorrentes da globalização e do modo capitalista de viver, onde viver só fará sentido se consumirmos mais e mais (ARAÚJO; VETTORAZZI, 2010).

Seguindo uma abordagem transversal, a educação pode levar a mudanças no comportamento e à incorporação de escolhas pró-ambientais da vida diária (CANDAMIO et al., 2018). Estes comportamentos indicam decisões e preferências que algumas pessoas vão adotando pouco a pouco, conforme vão incorporando a ideia de que as preocupações ambientais são importantes e, ao fazerem isso, sentem-se gratificadas e reconfortadas, mesmo sabendo que os riscos ambientais não se resolvem imediatamente com essas ações exemplares. A adoção desse espírito de cuidado, responsabilidade e solidariedade com o meio ambiente, representa uma dimensão "ecológica" que pode ser assumida por indivíduos, grupos e também pelas instituições como a escola ou as políticas públicas (CARVALHO, 2013).

Essa dimensão ecológica configurará o que se entende por sujeito ecológico, que é a representação ideal de um sujeito que baseia suas atitudes nas consequências ambientais que causa. O sujeito ecológico, dessa forma, é aquele que agrega a sua constituição subjetiva a atitude ecológica e, embora a formação do sujeito ecológico tenha lugar em todas as experiências que nos formam durante a vida, a escola toma parte entre estas experiências como um elo muito importante deste ambiente-mundo em que vivemos (CARVALHO, 2013).

Atitude ecológica, por sua vez, diz respeito a predisposições para que o sujeito apresente um comportamento ecologicamente orientado (GIRON; FERRARO, 2018). Mas, além da adoção da dimensão ecológica no modo de vida dos indivíduos, há também uma adaptação das dimensões financeira, ambiental, cultural e social do desenvolvimento sustentável, levando em consideração o modo e os meios de produção (EFING; RABELO, 2020). Trata-se de um modo de vida que visa transformar a realidade social, gerando assim uma consciência ambiental, de cuidados com a natureza e compreensão da finitude dos recursos naturais, que representa um grave problema decorrente do modelo de sociedade baseada na produção e consumo (MUTZ, 2014).

Assim sendo, caberá ao indivíduo questionar criticamente se será possível alcançar o modelo desenvolvimento sustentável que supere o antropocentrismo, bem como se irá alterar as relações de poder que subjuga seres humanos e a natureza. A problematização de tais propostas é uma postura cidadã que se faz pelo exercício crítico na produção social do espaço (GUIMARÃES, 2016). O enfoque do consumo no desenvolvimento sustentável está ligado ao processo da economia circular, em que haja garantia do ciclo de renovação e processo de reaproveitamento de toda a matéria prima presente na cadeia produtiva.

O conceito de consumo consciente é definido também como o consumo de bens e serviços que levem em consideração o respeito aos recursos ambientais e que garanta o atendimento das necessidades das presentes gerações, sem comprometer o atendimento das futuras (TÓDERO; MACKE; BIASUZ, 2011). Esta revisão do comportamento de consumo é cada vez mais necessária e importante diante dos desafios da mudança climática e da desvinculação da produção industrial à queima de combustíveis fósseis.

A referida transformação de comportamento dará às 
formas de consumo um novo objetivo, moldado pelas mudanças culturais, que buscam uma melhoria na relação homem x natureza em curto e longo prazo (EFING; RABELO, 2020). A desvinculação humanidade-natureza implica em também desvincular conflitos sociais e ambientais. Implica em classificar o ato humano como artificial e caracterizar sua interação com o ambiente como normalmente prejudicial. A separação entre humanidade e natureza não só tira a humanidade da natureza, como tira a natureza da humanidade (GIRON; FERRARO, 2018).

O desenvolvimento do pensamento crítico, habilitado através da EA, irá propor a revisão de hábitos de consumo e da supervalorização das "coisas" em detrimento da natureza. A partir dessa conscientização ambiental e significação prática dos elementos norteadores do desenvolvimento sustentável, os seres humanos passarão de meras vítimas da sociedade líquida, para consumidores conscientes de um novo modelo de sociedade, mais justo, humano e solidário para com os valores socioambientais (ARAÚJO; VETTORAZZI, 2010; BALDISSERA; PILAU SOBRINHO, 2017;).

Mesmo para quem se identifica com a proposta ecológica, destaca-se a necessidade de se estabelecer, constantemente, uma negociação intrapessoal, interpessoal, e política, em torno das decisões do dia a dia. Nesse sentido, a busca por uma vida guiada pelos ideais de um sujeito ecológico não isenta as pessoas das contradições, conflitos e negociações que sempre acontecem entre nossa realidade imperfeita e os nossos melhores ideais (CARVALHO, 2013). Essa negociação deriva da dificuldade de o mercado de produtos verdes estar ao alcance de todos os consumidores no local e momento exatos, bem como de preços plausíveis que assegurem o poder de compra de todos os consumidores.

Neste contexto, esta pesquisa propõe uma análise do comportamento de consumo e das escolhas de estudantes de graduação de uma universidade, bem como a relação destas escolhas com o incentivo recebido no ambiente escolar, com destaque para o conhecimento e preocupação com os principais desafios atuais da humanidade, como o combate à poluição plástica, desmatamento e o aquecimento global. Embora a educação tenha papel transformador na formação de indivíduos capazes de questionar o modelo econômico vigente, baseado no consumo intenso, descarte inadequado e escassez de tecnologias de reutilização de matérias prima, percebe-se que a EA nem sempre consegue obter resultados esperados, sob a perspectiva de maior valorização do meio ambiente e consumo sustentável.

Perante isso, esta pesquisa tem o objetivo de investigar o nível de percepção na escolha de consumo de jovens em nível de graduação, bem como analisar se o histórico de formação escolar destes jovens foi capaz de proporcionar o aumento da preocupação com o tema da sustentabilidade.

\section{Material e Métodos}

O presente estudo se caracteriza como um estudo de caso exploratório que, segundo Gil (2002) proporciona maior familiaridade com o problema, com vistas a torná-lo mais explícito ou a constituir hipóteses. O método de pesquisa utilizado foi de análise de conteúdo que, conforme Bardin (2010) caracteriza-se pelas seguintes fases de condução: organização da análise, codificação, categorização e tratamento dos resultados.

Assim sendo, partindo da organização da análise, buscamos elementos empíricos para vislumbre do comportamento de consumo e influência educacional dos sujeitos com atitudes mais ecológicas e procedemos com a elaboração de um questionário com base em fatores intrapessoais, motivacionais, interpessoais e educacionais.

Os participantes desta pesquisa compreenderam 21 estudantes de graduação de cursos diversos, da disciplina de Princípios e Práticas de Educação Ambiental, em uma universidade localizada na região metropolitana do estado do Rio Grande do Sul. Esse grupo de alunos respondeu a um questionário estruturado, no início do $2^{\circ}$ semestre escolar do ano de 2020. Antes da condução do questionário, testamos a aplicação em um pequeno grupo de indivíduos com o objetivo de verificar o entendimento e a consistência das respostas.

O questionário de 23 perguntas foi construído com base na literatura relevante acerca dos temas de EA e consumo consciente, e dividido em duas partes: a primeira solicitou informações qualitativas, para caracterização dos sujeitos respondentes, e a segunda caracterizou-se por questões relacionadas ao comportamento de consumo em uma escala de 1 a 5 pontos do tipo Likert, conforme Figura 1. De acordo com Jenkins e Taber (1977) e Lissitz e Green (1975), a escala de 5 pontos é suficiente, já que, por meio de simulações, não observaram um ganho de confiabilidade em escalas com mais que cinco itens.

Figura 1 - Descrição da escala de 5 pontos

\begin{tabular}{|c|c|c|c|c|}
\hline $\begin{array}{c}\text { Concordo } \\
\text { Plenamente }\end{array}$ & Concordo & $\begin{array}{c}\text { Nem } \\
\text { concordo } \\
\text { Nem } \\
\text { discordo }\end{array}$ & Discordo & $\begin{array}{c}\text { Discordo } \\
\text { Totalmente }\end{array}$ \\
\hline 1 & 2 & 3 & 4 & 5 \\
\hline
\end{tabular}

Fonte: Os autores (2020).

As perguntas foram respondidas obedecendo a escala de concordância em que: (1) significa consentimento pleno com o exposto; (2) aceitação; (3) neutralidade; (4) discordância e (5) desacordo total ao exposto.

A terceira fase na conduta da pesquisa constituiu de análise dos dados seguindo os estágios de categorização: comportamentos e crenças, informação e educação. Foi feita análise interpretativa dos dados coletados, através dos elementos oriundos da revisão teórica. A seguir são apresentados os resultados da pesquisa, bem como sua análise, à luz da revisão teórica. 


\section{Resultados e Discussão}

A grave crise socioambiental que se agravou nas últimas décadas, e que vem reproduzindo sucessivas "micro" crises climáticas, gera problemas locais e globais, com efeitos que demandam uma profunda reflexão crítica sobre como se dão suas causas. A reflexão demanda crítica acerca da interrelação Educação - Meio Ambiente - Sociedade e de que forma estas relações contribuíram para a atual crise climática.

Neste contexto, se faz imperativo destacar o papel da EA, por agregar um conjunto de elementos cognitivos e comportamentais, como consciência, conhecimento e atitudes na relação com os desafios ambientais, como habilidades necessárias para identificá-los e ajudar a resolvê-los. Sendo assim, é possível afirmar que a EA poderá contribuir para que os indivíduos possam sopesar os vários lados de uma questão por meio do pensamento crítico e aprimoramento das habilidades próprias de resolução de problemas e da tomada de decisões (CANDAMIO et al., 2018).

A EA surge como uma necessidade de enfrentamento à crise ambiental e suas consequências devastadoras. Como uma ferramenta para a resolução de um problema, é preciso, primeiramente, entender com profundidade seu objeto de ação. Se faz vital ir à raiz do problema socioambiental e ser radical na reflexão acerca das soluções, no aprimoramento do diálogo e ao teste. Chamar para a ação, assumindo seu papel na construção de outro modelo de sociedade e ser crítico (GIRON; FERRARO, 2018).

Sendo assim, a EA tem e terá forte caráter político, uma vez que instiga o pensamento crítico, contribui para a emancipação do sujeito, através da libertação dos elementos prejudiciais intrínsecos ao capitalismo, que permeiam a lógica perversa de exploração, com base no consumo e lucro como forma de atingir sucesso e aprisionam os indivíduos em uma lógica perversa de mercado. Assumir a dimensão política e cidadã da educação se faz essencial pelos educadores e demais agentes sociais, de forma a possibilitar a mudança dessa lógica (GUIMARÃES, 2016; REZENDE, 2014).

Ao considerar a concepção educacional de Paulo Freire (1921-1997), como balizadora de trabalhos de EA, destacamse os pressupostos, fundamentos e concepções inerentes à Pedagogia Freireana, que trazem implícita uma concepção de educação libertadora em contraposição a uma educação bancária. A educação libertadora é definida como aquela que transforma sujeitos passivos em conscientes, livres e mais humanos. Suas bases são o companheirismo, a autenticidade, a criticidade e a dialogicidade, na intervenção transformadora e na crença da humanização dos educadores e dos educandos (TORRES; MAESTRELLI, 2012).

Por meio da EA e da pedagogia libertadora Freireana, evidencia-se o processo de conscientização que, por ser práxis, implica na ação e reflexão dos educandos acerca de suas relações com e para com o mundo, tendo como horizonte a perspectiva de transformação cultural e social (TORRES;
MAESTRELLI, 2012). Porém, não é qualquer prática educativa que promove o despertar de uma consciência crítica, da mesma forma que não é qualquer proposta de EA que se propõe a formar uma atitude ecológica.

Dessa forma, a EA de caráter libertador, compreensivo da crise ambiental, passa pelo sentimento de pertencimento do sujeito subjetivamente interligado a causa ecológica, como ator social. Isso envolve uma cidadania ecológica, de modo que a atitude ecológica está associada a valores e visões de mundo mais permanentes (GIRON; FERRARO, 2018; CARVALHO, 2013). Práticas pedagógicas que reproduzem concepções tradicionais do pensamento educativo, baseada nos paradigmas modernos da sociedade, contribuem para a alienação ideológica do indivíduo que manterá a hegemonia da lógica de mercado.

$\mathrm{Na}$ referida perspectiva, Guimarães (2016) afirma que essa prática docente se mostra pouco eficaz para intervir significativamente no processo de transformação da realidade socioambiental, no âmbito da superação dos problemas e a construção de uma nova sociedade ambientalmente sustentável. Para isso ocorrer é necessária a união indissociável de teoria e prática, reflexão e ação, razão e emoção, indivíduo e coletivo, escola e comunidade.

Outros fatores de entrave à EA crítica nas escolas são destacados por Guimarães (2016): a concepção reducionista de meio ambiente, o entendimento de que as questões ambientais devem estar restritas às discussões por profissionais oriundos da Biologia e a limitada inserção da EA nos estudos da sociologia ambiental e da sociologia da educação. Nesse sentido, é importante destacar que o papel do educador ambiental não é apenas o do professor de ciências, pois a EA é interdisciplinar, devendo ser trabalhada por professores de diferentes áreas, visto que se caracteriza como um tema transversal (SCHWANKE et al., 2013).

Dado que a criticidade é uma aptidão natural a todos os seres humanos, é importante ressaltar que todos os professores (independente da área de formação) das séries iniciais deveriam estimular seus alunos a terem carinho, cuidado e respeito ao meio ambiente (GIRON; FERRARO, 2018; XIMENES; VIEIRA; ROQUE, 2018). As crianças podem ser estimuladas a ter uma visão crítico-reflexiva sobre os problemas associados às desigualdades e desarranjos nas relações entre o ser humano e o meio ambiente, sendo sua supressão resultado das condições sociais de opressão (GIRON; FERRARO, 2018; XIMENES; VIEIRA; ROQUE, 2018).

Também os educadores que desenvolvem suas atividades nos cursos de graduação universitária devem proporcionar uma formação pedagógica competente, mais próxima da realidade que os universitários encontrarão no futuro mercado de trabalho, com destaque para os cursos de graduação que visam formar os educadores de ensino fundamental e médio. Assim, os profissionais que virão para o mercado de trabalho estarão mais bem preparados para lidar com as questões 
ambientais de forma mais ampla e efetiva, de acordo com as necessidades contemporâneas e a realidade vivenciada nas escolas (XIMENES; VIEIRA; ROQUE, 2018).

Para Guimarães (2016) há diferentes propostas de EA, decorrentes de diferentes visões de mundo que as sustentam e que levam a resultados diferenciados. O projeto conservador, por exemplo, é baseado em uma visão liberal de mundo e que acredita que a transformação da sociedade é consequência da transformação de cada indivíduo, que são interpretados como seres em absoluta autonomia e orientados pela vontade individual. Já no projeto crítico a transformação da sociedade é causa e consequência da transformação de cada indivíduo, em que há uma reciprocidade dos processos no qual propicia a transformação de ambos.

Nesta visão, educando e educador são agentes sociais que atuam no processo de transformações sociais e nesse processo se transformam. A falta de crítica na EA direciona, para Brugger(1994), para um foco no "adestramento ambiental" que resume unicamente o caráter comportamental/individualista do processo educativo à transmissão de conhecimentos e mudanças de comportamento, desconsiderando a percepção da complexidade ambiental e para a transformação social.

As práticas alinhadas à EA crítica procuram relacionar os problemas ambientais a suas causas sociais, fazendo essa associação por meio da problematização das consequências ambientais de uma sociedade consumista e desigual, evidenciando os mecanismos de exploração que são responsáveis tanto pela miséria humana, quanto pela degradação ambiental (GIRON; FERRARO, 2018). Para Rezende (2014) a EA deve ter como base o pensamento crítico e inovador, em qualquer tempo ou lugar, em seus modos formal, não formal e informal, promovendo a transformação e a construção da sociedade.

Partindo do pressuposto da alta influência da EA no comportamento do consumidor, ao estabelecer razões críticas que favorecem o consumo sustentável, resolvemos investigar junto a uma turma da disciplina de Educação Ambiental em uma universidade, qual o grau de consciência ecológica desses indivíduos quanto a suas escolhas cotidianas, bem como a influência da educação formadora em seu comportamento. Para atingir tal objetivo, aplicamos um questionário com 23 questões, sendo 20 de análise comportamental de escala Likert.

O total de respondentes foi de 21 alunos, sendo o perfil deles: 15 mulheres e 6 homens, de idades variadas, entre 19 e 32 anos. A Figura 2 apresenta os cursos de graduação cursados pelos respondentes, que estavam matriculados na disciplina de Educação Ambiental. Conforme descrito pela figura, a maioria dos entrevistados afirmou estar cursando graduação em Ciências Biológicas (15 ou 71\% dos entrevistados) e os demais espalhados em áreas diversas, tais como: Engenharia Civil (2), Design e Animação (1), Farmácia (1), Publicidade e Propaganda (1) e Quiropraxia (1).
Figura 2 - Descrição gráfica dos cursos de graduação cursados pelos respondentes

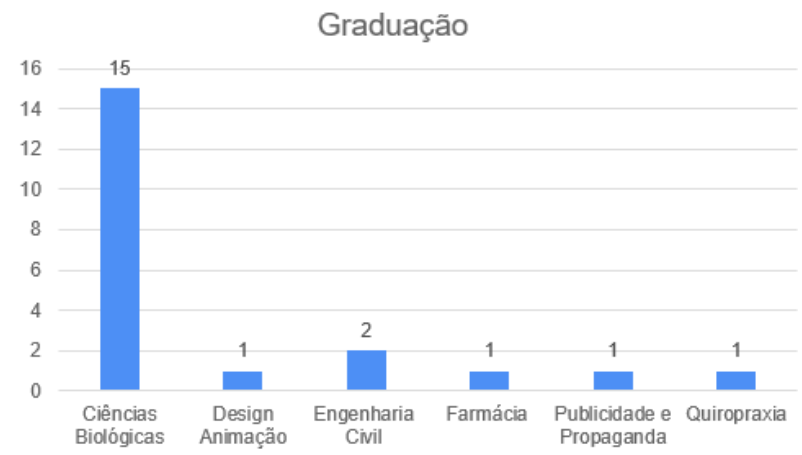

Fonte: Dados da pesquisa.

Quanto aos resultados obtidos para cada uma das afirmações contidas na categoria de Comportamento e Crenças, a maioria dos respondentes (66\%) afirma que preferem comprar produtos que contenham algum selo verde, de sustentabilidade e que adotam medidas com base na preocupação ambiental (52\%). Quanto ao aquecimento global, desmatamento e poluição plástica, todos os alunos concordaram plenamente ou concordaram com as afirmações de que se preocupam com estes temas, representando $81 \%$, $90 \%$ e $90 \%$ do total, respectivamente.

O resultado corrobora com o que destacou o Guimarães (2016), de que há amplo consenso na sociedade acerca dos problemas ambientais, mas que não significa consequentemente que estão sendo tomado medidas cabíveis para contorná-los. Um exemplo disso é que a maioria dos entrevistados (66\%), são indiferentes quanto a escolhas básicas como a compra de embalagens retornáveis ao invés das descartáveis.

Conforme Araújo e Vettorazzi (2010), o comportamento verde não é apenas o resultado de condições de controle estatal por meio de leis e normas, mas surge dos valores intrapessoais mantidos pelos cidadãos. De acordo com os autores, o Estado sozinho não será capaz de resolver os problemas ambientais decorrentes da globalização e do modo capitalista de viver.

A percepção da importância do papel do indivíduo através de seus hábitos de consumo ficou evidenciada, já que os resultados demonstraram a crença de que os consumidores têm forte papel no alcance dos objetivos do desenvolvimento sustentável (66\%), a frente das empresas (57\%) e do Governo $(52 \%)$.

A negociação interpessoal constante e os conflitos e contradições entre o real e o ideal (CARVALHO, 2013) ficou bastante explicitado, uma vez que o fator preço demonstrou um certo peso na atitude dos consumidores, sendo que $19 \%$ revelaram a influência negativa na sua decisão. 
Quadro 1 - Respostas do questionário na categoria Comportamento e Crenças

\begin{tabular}{|c|c|}
\hline Frase & \multirow[b]{2}{*}{ Porcentagem } \\
\hline $\begin{array}{c}\text { Prefiro comprar produtos com embalagem } \\
\text { descartável }\end{array}$ & \\
\hline Concordo Totalmente & $14 \%$ \\
\hline Concordo & $19 \%$ \\
\hline Nem Concordo Nem Discordo & $24 \%$ \\
\hline Discordo & $14 \%$ \\
\hline Discordo Totalmente & $28 \%$ \\
\hline \multicolumn{2}{|c|}{ Prefiro comprar produtos com selo de sustentabilidade } \\
\hline Concordo Totalmente & $43 \%$ \\
\hline Concordo & $24 \%$ \\
\hline Nem Concordo Nem Discordo & $24 \%$ \\
\hline Discordo & $9 \%$ \\
\hline \multicolumn{2}{|c|}{$\begin{array}{l}\text { Adoto medidas com base em preocupação com o meio } \\
\text { ambiente }\end{array}$} \\
\hline Concordo Totalmente & $52 \%$ \\
\hline Concordo & $38 \%$ \\
\hline Nem Concordo Nem Discordo & $5 \%$ \\
\hline Discordo & $5 \%$ \\
\hline \multicolumn{2}{|l|}{ Me preocupo com o aquecimento global } \\
\hline Concordo Totalmente & $81 \%$ \\
\hline Concordo & $19 \%$ \\
\hline \multicolumn{2}{|l|}{ Me preocupo com a poluição plástica } \\
\hline Concordo Totalmente & $90 \%$ \\
\hline Concordo & $10 \%$ \\
\hline \multicolumn{2}{|l|}{ Me preocupo com o desmatamento } \\
\hline Concordo Totalmente & $90 \%$ \\
\hline Concordo & $10 \%$ \\
\hline \multicolumn{2}{|c|}{$\begin{array}{l}\text { Acredito que a mudança de hábitos de consumo pode } \\
\text { contribuir para o desenvolvimento sustentável }\end{array}$} \\
\hline Concordo Totalmente & $100 \%$ \\
\hline \multicolumn{2}{|c|}{ Aceito pagar mais por produto com apelo sustentável } \\
\hline Concordo Totalmente & $48 \%$ \\
\hline Concordo & $33 \%$ \\
\hline Nem Concordo Nem Discordo & $10 \%$ \\
\hline Discordo & $5 \%$ \\
\hline Discordo Totalmente & $5 \%$ \\
\hline \multicolumn{2}{|c|}{$\begin{array}{l}\text { Me considero um consumidor consciente sob a perspectiva } \\
\text { sustentável }\end{array}$} \\
\hline Concordo Totalmente & $24 \%$ \\
\hline Concordo & $24 \%$ \\
\hline Nem Concordo Nem Discordo & $48 \%$ \\
\hline Discordo Totalmente & $5 \%$ \\
\hline
\end{tabular}

Fonte: Dados da pesquisa.

Porém, quando o assunto é economia circular, ainda existe alguma dúvida perante os alunos sobre o seu significado, já que $24 \%$ não afirmaram tratar-se dos resíduos que serão aproveitados como matéria prima em outras organizações. Os resultados positivos demonstrados nessa categoria demonstram que os temas estão bem difundidos nos principais meios de comunicação onde os jovens estão inseridos, e que há consciência quanto a necessidade do alcance de maiores informações à sociedade para alavancar a mudança de hábitos.

Será a partir da conscientização ambiental e significação prática dos elementos norteadores do desenvolvimento sustentável, que os seres humanos passarão de meras vítimas da sociedade para consumidores conscientes de um novo modelo de sociedade, mais aderente para com os valores socioambientais (ARAÚJO; VETTORAZZI, 2010; BALDISSERA; PILAU SOBRINHO, 2017).

Apesar de todos os alunos concordarem com a necessidade de mudanças de hábitos para alavancar o desenvolvimento sustentável, $9 \%$ da turma não adota medidas mais ecológicas, e 19\% não aceitaria pagar mais caro por produtos de apelo sustentável. A maioria (52\%) não se julga consumidor totalmente consciente, o que releva que, apesar da disponibilidade de informações e o conhecimento dos principais problemas ambientais, falta atitude e a preferência por produtos mais ecológicos.

Fatores intrapessoais e a carência de uma EA mais aplicada para a motivação, podem explicar a ausência de atitudes e hábitos mais explícitos. Hábitos relacionados a conscientização do consumo, precisam ser inseridos no contexto escolar (CANDAMIO et al., 2018; SILVA; COSTA; BORBA, 2016). E esse ser crítico que pode ser moldado através da EA, irá ser motivado para a ação e não apenas para o estabelecimento de conceitos teóricos de entendimento da problemática ambiental (BRUGGER, 1994; GIRON; FERRARO, 2018; REZENDE, 2014).

Quanto as afirmações que compõe a categoria de análise, o Quadro 2 detalha o percentual obtido para cada uma das respostas.

Quadro 2 - Respostas do questionário na categoria Informação

\begin{tabular}{|l|c|}
\hline \multicolumn{1}{|c|}{ Frase } & \multirow{2}{*}{ Porcentagem } \\
\cline { 1 - 2 } $\begin{array}{l}\text { O desenvolvimento sustentável deve ser } \\
\text { responsabilidade do governo }\end{array}$ & $33 \%$ \\
\hline Concordo Totalmente & $19 \%$ \\
\hline Concordo & $24 \%$ \\
\hline Nem Concordo Nem Discordo & $10 \%$ \\
\hline Discordo & $15 \%$ \\
\hline Discordo Totalmente & \\
\hline
\end{tabular}

O desenvolvimento sustentável deve ser responsabilidade das empresas

\begin{tabular}{|l|c|}
\hline Concordo Totalmente & $29 \%$ \\
\hline Concordo & $29 \%$ \\
\hline Nem Concordo Nem Discordo & $29 \%$ \\
\hline Discordo & $10 \%$ \\
\hline Discordo Totalmente & $5 \%$ \\
\hline
\end{tabular}

O desenvolvimento sustentável deve ser responsabilidade do consumidor

\begin{tabular}{|l|l}
\hline Concordo Totalmente & $38 \%$ \\
\hline Concordo
\end{tabular}

\begin{tabular}{|l|l}
\hline Concordo & $29 \%$ \\
\hline
\end{tabular}

\begin{tabular}{|l|r}
\hline Nem Concordo Nem Discordo & $24 \%$ \\
\hline Discordo
\end{tabular}

Discordo

Discordo Totalmente

$5 \%$

Produto reciclável é aquele que ao final de sua vida útil pode ser reintroduzido na economia

\begin{tabular}{|l|l}
\hline Concordo Totalmente & $81 \%$
\end{tabular}

\begin{tabular}{|l|r}
\hline Concordo & $15 \%$ \\
\hline
\end{tabular}

\begin{tabular}{|l|r}
\hline Nem Concordo Nem Discordo & $4 \%$ \\
\hline
\end{tabular}

Material biodegradável é aquele que se decompõe mais rapidamente e prejudica menos 0 ambiente 


\begin{tabular}{|c|c|}
\hline Concordo Totalmente & $71 \%$ \\
\hline Concordo & $29 \%$ \\
\hline \multicolumn{2}{|c|}{$\begin{array}{l}\text { Sustentabilidade envolve desenvolvimento em harmonia } \\
\text { com o meio ambiente para não comprometer o futuro das } \\
\text { próximas gerações }\end{array}$} \\
\hline Concordo Totalmente & $86 \%$ \\
\hline Concordo & $14 \%$ \\
\hline \multicolumn{2}{|c|}{$\begin{array}{l}\text { Na Economia Circular os resíduos de uma organização } \\
\text { representam matéria prima em outra }\end{array}$} \\
\hline Concordo Totalmente & $43 \%$ \\
\hline Concordo & $33 \%$ \\
\hline Nem Concordo Nem Discordo & $24 \%$ \\
\hline \multicolumn{2}{|c|}{$\begin{array}{l}\text { A mudança de hábitos de consumo pode ser decorrente de } \\
\text { mais informações sobre a sustentabilidade ambiental }\end{array}$} \\
\hline Concordo Totalmente & $76 \%$ \\
\hline Concordo & $19 \%$ \\
\hline Nem Concordo Nem Discordo & $5 \%$ \\
\hline
\end{tabular}

Fonte: Dados da pesquisa.

Quanto a dimensão da Educação no reflexo das atitudes dos entrevistados, $48 \%$ dos alunos não afirmaram que estimúlos recebidos no ambiente escolar tenham contribuído para torná-los mais conscientes, revelando o que outros autores já evidenciaram em estudos pertinentes ao tema, de que mais EA e conhecimento teórico, não está estimulando os alunos para torná-los mais críticos perante a suas escolhas e o ato do consumismo (CANDAMIO et al., 2018; GUIMARÃES, 2016; SILVA; COSTA; BORBA, 2016).

O Quadro 3 apresenta os resultados obtidos para cada uma das afirmações, o percentual de concordância ou não e a representação gráfica. Os resultados demonstram que se faz necessária a mudança de mentalidade e necessidade de "desmaterializar" o consumo material, consumo esse que é muitas vezes associado a realização econômica e de status pessoal (ARAÚJO; VETTORAZZI, 2010).

Quadro 3 - Respostas do questionário na categoria Educação

\begin{tabular}{|l|c|}
\hline \multicolumn{1}{|c|}{ Frase } & \multirow{2}{|c|}{ Porcentagem } \\
\cline { 1 - 2 } $\begin{array}{l}\text { Atitudes sustentáveis devem ser praticadas } \\
\text { apenas por grupos ligados ao meio ambiente }\end{array}$ & $100 \%$ \\
\hline Discordo Totalmente & $10 \%$ \\
\hline $\begin{array}{l}\text { Me tornei ambientalmente consciente a partir de estímulos } \\
\text { que recebi no ambiente escolar }\end{array}$ & $43 \%$ \\
\hline Concordo Totalmente & $29 \%$ \\
\hline Concordo & $14 \%$ \\
\hline Nem Concordo Nem Discordo & $5 \%$ \\
\hline Discordo & $52 \%$ \\
\hline Discordo Totalmente & $19 \%$ \\
\hline $\begin{array}{l}\text { Incentivo as pessoas a minha volta a consumirem produtos } \\
\text { visando os cuidados ambientais }\end{array}$ & $19 \%$ \\
\hline Concordo Totalmente & $10 \%$ \\
\hline Concordo & \\
\hline Nem Concordo Nem Discordo & \\
\hline Discordo & \\
\hline
\end{tabular}

Fonte: Dados da pesquisa.

O consumo que está diretamente ligado ao prazer, prazer definido como imediato, conforme afirmam Efing e Rabelo (2020) e que precisa ser repensado pois, o consumo consciente influencia na melhora da qualidade dos produtos e serviços ofertados no mercado, contribuindo com um menor impacto para o meio ambiente. Ou seja, é preciso repensar o modelo de consumo, para que as mudanças ambientais sejam efetivas.

Os resultados corroboram para o entendimento de Candamio et al. (2018) de que EA não pode ser materializada apenas com conhecimento teórico, mas com o cumprimento de ações que visam a mudança responsável através de atitudes. Grande parte do sistema educacional não forma alunos com vistas à preservação da biodiversidade, a cooperação ambiental e a sustentabilidade (SILVA; COSTA; BORBA, 2016).

O nível de concordância com a afirmação de que os entrevistados incentivam as pessoas ao seu redor a consumirem produtos com vistas aos cuidados ambientais foi de 1,86 , com alto grau de concordância, conforme apresentado no Quadro 4. Essa afirmação confirma ainda mais a sustentação de que há consciência e entedimento sobre a interdisciplinariedade do tema ambiental, mas no geral das respostas obtidas, verificase que o comportamento humano ainda é uma barreira para acentuar ações concretas, reforçando que essa mudança nos padrões de consumo é um processo complexo, que requer grandes mudanças na forma de pensar, na consciência ambiental e que interfere diretamente no aspecto financeiro.

Quadro 4-Respostas médias por categoria de análise e afirmação

\begin{tabular}{|c|c|c|}
\hline $\begin{array}{l}\text { Categoria de } \\
\text { Análise }\end{array}$ & Frase & $\begin{array}{c}\text { Resposta } \\
\text { Média }\end{array}$ \\
\hline \multirow{10}{*}{$\begin{array}{c}\text { Comportamento } \\
\text { / Crenças }\end{array}$} & $\begin{array}{l}\text { Prefiro comprar produtos com } \\
\text { embalagem descartável } * *\end{array}$ & 3,23 \\
\hline & $\begin{array}{l}\text { Prefiro comprar produtos com } \\
\text { selo de sustentabilidade }\end{array}$ & 2 \\
\hline & $\begin{array}{l}\text { Adoto medidas com base } \\
\text { em preocupação com o meio } \\
\text { ambiente }\end{array}$ & 1,61 \\
\hline & $\begin{array}{l}\text { Me preocupo com o } \\
\text { aquecimento global }\end{array}$ & 1,19 \\
\hline & $\begin{array}{l}\text { Me preocupo com a poluição } \\
\text { plástica }\end{array}$ & 1,09 \\
\hline & $\begin{array}{l}\text { Me preocupo com o } \\
\text { desmatamento }\end{array}$ & 1,09 \\
\hline & $\begin{array}{l}\text { Acredito que a mudança } \\
\text { de hábitos de consumo } \\
\text { pode contribuir para o } \\
\text { desenvolvimento sustentável } \\
\end{array}$ & 1 \\
\hline & $\begin{array}{l}\text { Aceito pagar mais por produto } \\
\text { com apelo sustentável }\end{array}$ & 1,85 \\
\hline & $\begin{array}{l}\text { Me considero um consumidor } \\
\text { consciente sob a perspectiva } \\
\text { sustentável }\end{array}$ & 2,38 \\
\hline & $\begin{array}{l}\text { MÉDIA }(* * \text { retirado da } \\
\text { contagem) }\end{array}$ & 2 \\
\hline \multirow{2}{*}{ Informação } & $\begin{array}{l}\text { O desenvolvimento sustentável } \\
\text { deve ser responsabilidade do } \\
\text { governo }\end{array}$ & 2,52 \\
\hline & $\begin{array}{l}\text { O desenvolvimento sustentável } \\
\text { deve ser responsabilidade das } \\
\text { empresas }\end{array}$ & 2,33 \\
\hline
\end{tabular}




\begin{tabular}{|c|c|c|}
\hline $\begin{array}{c}\text { Categoria de } \\
\text { Análise }\end{array}$ & Frase & $\begin{array}{c}\text { Resposta } \\
\text { Média }\end{array}$ \\
\hline \multirow{7}{*}{ Informação } & $\begin{array}{l}\text { O desenvolvimento sustentável } \\
\text { deve ser responsabilidade do } \\
\text { consumidor }\end{array}$ & 2,09 \\
\hline & $\begin{array}{l}\text { Produto reciclável é aquele que } \\
\text { ao final de sua vida útil pode ser } \\
\text { reintroduzido na economia }\end{array}$ & 1,23 \\
\hline & $\begin{array}{l}\text { Material biodegradável é } \\
\text { aquele que se decompõe mais } \\
\text { rapidamente e prejudica menos } \\
\text { o ambiente }\end{array}$ & 1,28 \\
\hline & $\begin{array}{l}\text { Sustentabilidade envolve } \\
\text { desenvolvimento em harmonia } \\
\text { com o meio ambiente para } \\
\text { não comprometer o futuro das } \\
\text { próximas gerações }\end{array}$ & 1,14 \\
\hline & $\begin{array}{l}\text { Na Economia Circular os } \\
\text { resíduos de uma organização } \\
\text { representam matéria prima em } \\
\text { outra }\end{array}$ & 1,8 \\
\hline & $\begin{array}{l}\text { A mudança de hábitos de } \\
\text { consumo pode ser decorrente } \\
\text { de mais informações sobre a } \\
\text { sustentabilidade ambiental } \\
\end{array}$ & 1,28 \\
\hline & MÉDIA & 2 \\
\hline \multirow{4}{*}{ Educação } & $\begin{array}{l}\text { Atitudes sustentáveis devem ser } \\
\text { praticadas apenas por grupos } \\
\text { ligados ao meio ambiente }\end{array}$ & 5 \\
\hline & $\begin{array}{l}\text { Me tornei ambientalmente } \\
\text { consciente a partir de estímulos } \\
\text { que recebi no ambiente escolar }\end{array}$ & 2,62 \\
\hline & \begin{tabular}{|l|} 
Incentivo as pessoas a minha \\
volta a consumirem produtos \\
visando os cuidados ambientais
\end{tabular} & 1,86 \\
\hline & Média & 3 \\
\hline
\end{tabular}

Fonte: Dados da pesquisa.

Ao concordarem totalmente com a afirmação de que atitudes sustentáveis devem ser tomadas por todos os grupos, e não apenas os ligados ao meio ambiente, os entrevistados mostram a consciência da importância da interdisciplinaridade da EA como propulsora para consciência ecológica (SCHWANKE et al., 2013).

O Quadro 4 apresenta a média global dos graus de concordância obtidos em cada uma das categorias de análise e escalas médias por cada afirmação. A primeira afirmação - "Prefiro comprar produtos com embalagem descartável", foi retirada da contagem da média, pois a escala tinha lógica diferente das demais questões, sendo as respostas de 1-3 pontos com impacto negativo na escala ecológica. A resposta média na categoria de análise Comportamento e Crenças foi de 2 pontos, ou seja, de concordância com preferências de consumo e preocupações com o meio ambiente e a sustentabilidade.

$\mathrm{Na}$ categoria de análise Informação, a média obtida nas respostas foi de 2 pontos, significando concordância com as afirmações sobre desenvolvimento sustentável e o conhecimento de assuntos ligados ao tema, revelando conhecimento prévio dos alunos sobre o significado dos conceitos de reciclagem, material biodegradável e sustentabilidade (95\%).

A média geral de concordância do fator Educação apresentou o resultado de 3 (nem concordo/nem discordo), sendo que assumir a dimensão política e cidadã da educação se faz essencial pelos educadores e demais agentes sociais, de forma a possibilitar a mudança dessa lógica (GUIMARÃES, 2016; REZENDE, 2014).

Assim sendo, os elementos advindos das respostas dos questionários, corroboram com os principais achados da revisão bibliográfica, em que a EA irá contribuir para que os indivíduos possam sopesar os vários lados de uma questão por meio do pensamento crítico e aprimoramento das habilidades próprias de resolução de problemas e da tomada de decisões. A ação, por conseguinte, será a consequência da incorporação do espírito crítico e da racionalidade, visando efetivamente alterar hábitos próprios de consumo e politizar-se, em prol de uma visão dinâmica de sociedade em que haja o predomínio do resgate dos valores humanos relacionados aos elementos naturais (CANDAMIO et al., 2018; SILVA; COSTA; BORBA, 2016).

\section{Conclusão}

Enquanto o Estado tem o dever de garantir políticas públicas que promovam a defesa do meio ambiente, a iniciativa privada e o cidadão-consumidor também devem assumir seu papel de responsabilidade a favor do meio ambiente. Esse processo progressivo de despertar de consciência e de responsabilidade, que resulta de valores sociais e afirmação cidadã, precisa ser construído desde a infância, no início do processo escolar.

A EA de qualidade deve formar cidadãos questionadores e capazes de refletirem acerca de seus hábitos de consumo e serem capazes de tomar as atitudes certas. Sendo assim, a EA deve perpassar a simples inserção curricular no ensino, mas estar presente nos debates em sala de aula, em qualquer que seja a disciplina.

Neste sentido, esta pesquisa objetivou investigar qual o grau de consciência ecológica de estudantes de graduação, que cursavam uma disciplina de Educação Ambiental multidisciplinar. Este estudou visou inquirir a motivação das escolhas cotidianas dos estudantes, bem como a influência da educação formadora neste comportamento. Os resultados desta pesquisa identificaram a necessidade de aprimoramento de um ensino ambiental voltado para a mudança de atitudes e hábitos de consumo, não apenar ater-se a teoria e ambiente interno de sala de aula.

A dimensão individual e subjetiva dos alunos deve ser mais bem compreendida pelos educadores, a fim de que essa aproximação possa romper os obstáculos que paralisam o sujeito na tomada de atitudes mais concretas a favor do meio ambiente.

Propostas pedagógicas que proponham práticas de conscientização para maior compreensão de todo o processo 
de consumo, sua dinâmica e consequência são temáticas relevantes frente a realidade e que se confirma com o resultado dos questionários aplicados. Para pesquisas futuras, recomendamos o aumento do número de indivíduos para participação na pesquisa, bem como a aplicação em diferentes áreas geográficas e contextos escolares.

\section{Referências}

ARAÚJO, J.S.; VETTORAZZI, K.M. A sustentabilidade de produtos e serviços enquanto pré-requisito ao consumo consciente. Rev. Direito Econ. Socioamb., v.1, n.1, p.109-126, 2010. doi: 10.7213/rev.dir.econ.soc.v8i1.7538.

BALDISSERA, R.; PILAU SOBRINHO, L.L.O homem pósmoderno como vítima colateral da sociedade de consumo. Rev. Direito Sustentabil., v.3, p.17-34, 2017. doi: 10.26668/ IndexLawJournals/2525-9687/2017.v3i1.2172.

BARDIN, L. Análise de conteúdo. Lisboa: Edições 70, 2010.

BRUGGER, P. Educação ou adestramento ambiental. Santa Catarina: Letras Contemporâneas, 1994.

CANDAMIO, L.V.; CORTI, I.N.; ALVAREZ, M.T.G. The importance of environmental education in the determinants of green behavior: A meta-analysis approach. J. Cleaner Production, v.170, p.1565-1578, 2018. doi: 10.1016/j.jclepro.2017.09.214.

CARVALHO, I.C.M. O sujeito ecológico: a formação de novas identidades na escola. In: PERNAMBUCO, M.; PAIVA, I. (Org.). Práticas coletivas na escola. Campinas: Mercado de Letras, 2013. p.115-124.

EFING, A.C.; RABELO, C.A. Consumo consciente e a instalação de redes elétricas inteligentes para um desenvolvimento sustentável. 2020. doi: 10.25245/rdspp.v8i1.503.

GIL, A.C. Como elaborar projetos de pesquisa. São Paulo, Atlas, 2002.

GIRON, H.; FERRARO, J.L.S. Uma proposta de diálogo entre Paulo Freire e a Educação Ambiental Crítica. Rev. Eletr. Mestr. Educ. Ambient., n.1, p.239-252, 2018. doi: 10.14295/remea. v0i1.8576.

GUIMARÃES, M. Por uma educação ambiental crítica na sociedade atual. Rev. Margens Interdisc., 2016. doi: http://dx.doi. org/10.18542/rmi.v7i9.2767.

JENKINS, G.D.; TABER, T.D. A Monte Carlo study of factors affecting three indices of composite scale reliability. J. Appl. Psychol., v.62, n.4, p.392-398, 1977. doi: 10.1037/00219010.62.4.392.

LISSITZ, R.W; Green S.B. Effect of the number of scale points on reliability: a Monte Carlo approach. J. Appl. Psychol., v. 60, n. 1, p.10-13, 1975. doi: 10.1037/h0076268.

MUTZ, A.S.C. O discurso do consumo consciente e a produção dos sujeitos contemporâneos do consumo. Educ. Rev., v.30, n.2, p.117-136, 2014. doi: 10.1590/S0102-46982014005000001.

REZENDE, V.A. (2014). A dimensão ambiental na educação de jovens e adultos: possibilidades e desafios. Rev. Tempos Espaços Educ., p.67-76, 2014. doi: 10.20952/revtee.v0i0.2542.

SCHWANKE, $C$. et al.Construindo cidadania ambiental na escola. Rev. Eletr. Extensão, v.10, n.16, p.14-22, 2013. doi: 10.5007/1807-0221.2013v10n16p14.

SILVA, C.M.L.F.; COSTA, F.A.; BORBA, G.L. A educação em mudanças climáticas: uma abordagem interdisciplinar. Holos, v.32, 2016. doi: 10.15628/holos.2016.3950.

STRIFE, S. Reflecting on environmental education: where is our place in the Green Movement? J. Environ. Educ., v.41, n.3, p.179-191, 2010. doi: 10.1080/00958960903295233.

TÓDERO, M.; MACKE, J.; BIASUZ, T.S. The conscientious consumption and the relation with the enterprise social actions for damages. 2011. doi: 10.24857/rgsa.v5i1.284.

TORRES, J.R.; MAESTRELLI, S.R.P. Apropriações da concepção educacional de Paulo Freire na educação ambiental: um olhar crítico. Rev. Contemp. Educ., v.7, n.14, 2012. doi: 10.20500/rce.v7i14.1674.

XIMENES, L.S.V.; VIEIRA, D.S.; ROQUE, F.A.R.L. Environmental education: training tool for stimulating conscious since initial school grades. Environ. Smoke. v.1, n. 2, 2018. doi: 10.32435/envsmoke.20181201-14.

WALS, A.E.J. et al. Convergence between science and environmental education. Science, v.344. n.6184, p.583-584, 2014. 